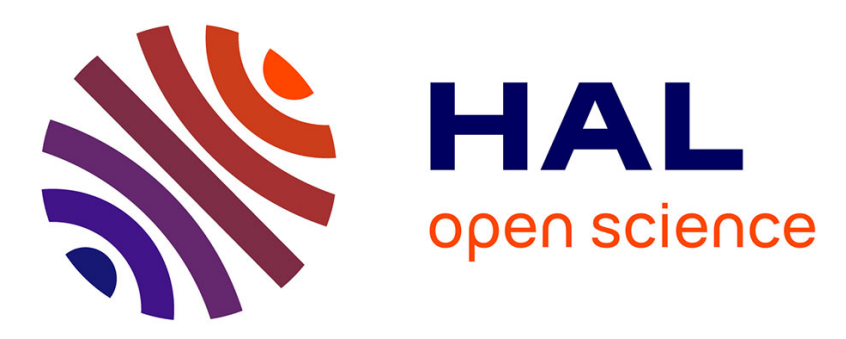

\title{
Photoredox-Catalyzed Selective Synthesis of Allylic Perfluoroalkanes from Alkenes
}

Anne-laure Barthelemy, F. Bourdreux, Guillaume Dagousset, Emmanuel

Magnier

\section{- To cite this version:}

Anne-laure Barthelemy, F. Bourdreux, Guillaume Dagousset, Emmanuel Magnier. PhotoredoxCatalyzed Selective Synthesis of Allylic Perfluoroalkanes from Alkenes. Chemistry - A European Journal, 2020, 26 (45), pp.10213-10216. 10.1002/chem.202002046 . hal-02992795

\section{HAL Id: hal-02992795 \\ https://hal.science/hal-02992795}

Submitted on 6 Nov 2020

HAL is a multi-disciplinary open access archive for the deposit and dissemination of scientific research documents, whether they are published or not. The documents may come from teaching and research institutions in France or abroad, or from public or private research centers.
L'archive ouverte pluridisciplinaire HAL, est destinée au dépôt et à la diffusion de documents scientifiques de niveau recherche, publiés ou non, émanant des établissements d'enseignement et de recherche français ou étrangers, des laboratoires publics ou privés. 


\title{
Photoredox-Catalyzed Selective Synthesis of Allylic Perfluoroalkanes from Alkenes
}

\author{
Anne-Laure Barthelemy, F. Bourdreux, Guillaume Dagousset, ${ }^{*}$ and Emmanuel Magnier*
}

\begin{abstract}
We report herein a novel photoredox-catalyzed synthesis of allylic trifluoromethanes. The use of sulfilimino iminium as source of trifluoromethyl radical proves crucial to achieve high selectivity. Importantly, both styrene derivatives and unactivated alkenes are for the first time suitable partners for this process. The mild reaction conditions are compatible with a variety of functional groups. Remarkably, this method is readily broadened to other perfluoroalkyl groups $\left(\mathrm{R}_{\mathrm{F}}=\mathrm{CFCl}_{2}, \mathrm{CF}_{2} \mathrm{Br}, \mathrm{C}_{4} \mathrm{~F}_{9}\right)$. An extensive mechanistic study is also provided.
\end{abstract}

The presence of a trifluoromethyl group (or perfluoroalkyl group $\mathrm{R}_{\mathrm{F}}$ ) into organic compounds is of great importance due to the specific physico-chemical properties that such $\mathrm{CF}_{3}$ moiety imparts on these molecules (high lipophilicity, improved bioavailability and enhanced metabolic stability). ${ }^{[1]}$ Among the contemporary synthetic approaches available to create a new $\mathrm{C}_{-} \mathrm{CF}_{3}$ bond, visible-light photoredox-induced trifluoromethylation of alkenes has recently emerged as a prominent methodology. ${ }^{[2,3]}$ It often starts from one of the most available functional groups, a carbon-carbon double bond, is easy to put into practice and tolerant to a wide range of functional groups. On the one hand, this $\mathrm{C}_{-}-\mathrm{CF}_{3}$ bond formation can be combined with the concomitant introduction of a second functional group, leading to various vicinal difunctionalizations of alkenes. ${ }^{[2 a]}$ On the other hand, with a formal loss of a proton instead of a second functionalization, it can give access to either vinyl- $\mathrm{CF}_{3}$ or allyl- $\mathrm{CF}_{3}$ compounds, which have shown to be useful fluorinated moieties in medicinal chemistry and material sciences, ${ }^{[4]}$ and which can undergo further functionalization to access biologically active molecules. ${ }^{[5]}$

One of the major issues is then the selectivity between vinyland allyl- $\mathrm{CF}_{3}$ derivatives with emphasis on the production of the allylic targets (Scheme 1, box). Indeed, the selective photocatalytic synthesis of vinyl- $\mathrm{CF}_{3}$ (and more generally vinyl$R_{F}$ ) products from simple alkenes have been thoroughly described in the literature. ${ }^{[6]}$ In all these reports, a $R_{F}-X$ reagent $\left(\mathrm{X}=\right.$ halogen) was used as the source of $\cdot \mathrm{R}_{\mathrm{F}}$ radical, and evidence for a haloperfluoroalkylation/ $\mathrm{HX}$ elimination sequence were generally provided to account for the formation of the vinyl$\mathrm{CF}_{3}$ adduct (Scheme 1a). The elimination step is quite selective, and allyl- $\mathrm{CF}_{3}$ adducts were only detected in trace amounts. ${ }^{[6 \mathrm{~b}, 6 \mathrm{j}]}$ By contrast, the photocatalytic synthesis of allyl- $\mathrm{CF}_{3}$ compounds from alkenes has only been reported once, to the best of our knowledge. ${ }^{[7,8]}$ In this seminal and pioneering work, Koike, Akita and coworkers used Umemoto's reagent as the source of $\mathrm{CF}_{3}$ radical (Scheme $1 b$ ). However, a moderate allyl/vinyl selectivity was obtained in the case of terminal alkenes (2.6:1 to 1:1.4 ratio), and double trifluoromethylation was observed as sidereaction in the case of internal alkenes, leading mainly to poor yields.

[a] Dr. A.-L. Barthelemy, F. Bourdreux, Dr. G. Dagousset, Dr. E. Magnier

Université Paris-Saclay, UVSQ, CNRS, UMR 8180, Institut Lavoisier de Versailles, 78000, Versailles, France Fax: (+) 33139254452

E-mail: guillaume.dagousset@uvsq.fr; emmanuel.magnier@uvsq.fr

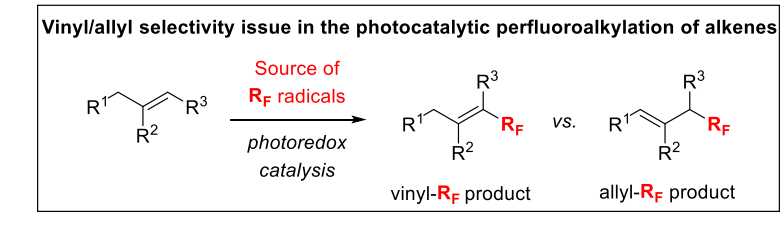

a) With $R_{F}-X(X=B r, I): \bullet$ Various widespread protocols

- High selectivity in favor of the vinyl- $R_{F}$ product

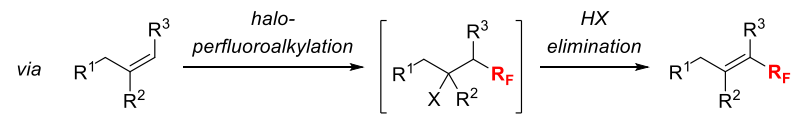

b) With Umemoto's reagent:

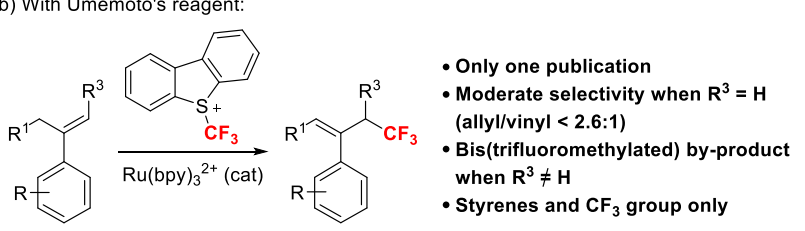

c) This work: with $\mathbf{R}_{\mathrm{F}}$-sulfilimino iminiums

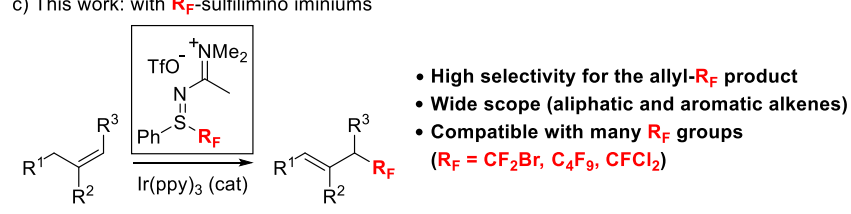

Scheme 1. Allyl vs. vinyl perfluoroalkylation of alkenes under photoredox catalysis. bpy $=2,2$ '-bipyridine. ppy $=2$-phenylpyridine.

As a consequence, a general method towards the selective formation of allyl- $\mathrm{CF}_{3}$ compounds from alkenes under photoredox catalysis is highly needed. ${ }^{[9]}$

In this context, we wish to report herein a new and general protocol of photoredox-catalyzed synthesis of allylic trifluoromethanes. Importantly, it proved highly selective for both aliphatic and aromatic alkenes, and was easily extended to a variety of other perfluoroalkyl groups (Scheme 1c).

Our initial investigations began with the reaction between alkene 1a (1 equiv), a $\mathrm{CF}_{3}$ source 2 (1 equiv), and fac-Ir(ppy) 3 as the photocatalyst in $\mathrm{CH}_{2} \mathrm{Cl}_{2}$ (Table 1). Blue LED irradiation of this mixture in the case of the well-known Umemoto's and Togni's reagents 2a-b led only to traces of the desired allyl- $\mathrm{CF}_{3}$ adduct 4a $(2 \%$ and $10 \%$, respectively, entries $1-2)$. Despite these low yields, the process was selective with respect to the formation of the corresponding vinyl- $\mathrm{CF}_{3}$ by-product $\mathbf{4} \mathbf{a}^{\prime}\left(\mathbf{4} \mathbf{a} / \mathbf{4} \mathbf{a}^{\prime}=\mathbf{4} \cdot 9: 1\right.$, entry 2). This result was consistent with the previous work of Koike and Akita, ${ }^{[7]}$ and encouraged us to test other sources of $\mathrm{CF}_{3}$ radical. Notably, switching to $\mathrm{S}-\mathrm{CF}_{3}$ sulfoximine derivatives $2 \mathrm{c}-\mathrm{e}$ resulted in improved yields, with somewhat similar allyl/vinyl selectivities (entries 3-5). Pleasingly, with sulfilimino iminium 2f, which has been recently used as an efficient precursor of $\mathrm{CF}_{3}$ radical under photoredox catalysis, ${ }^{[10]}$ product $\mathbf{4 a}$ was obtained in a better yield $(54 \%$, entry 6$)$, and remarkably, the allyl/vinyl selectivity was even higher $\left(\mathbf{4} \mathbf{a} / \mathbf{4} \mathbf{a}^{\prime}=12: 1\right)$. Other parameters, 
Table 1. Optimization of the photoredox-catalyzed allylic trifluoromethylation of alkene 1a.

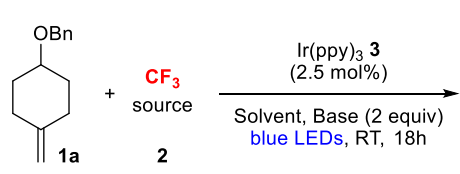<smiles>FC(F)(F)CC1=CCC(OCc2ccccc2)CC1</smiles><smiles>FC(F)(F)[Ge](c1ccccc1-c1ccccc1)(C(F)(F)F)C(F)(F)F</smiles>
${ }^{2 a}{ }^{\mathrm{CF}_{3}}$

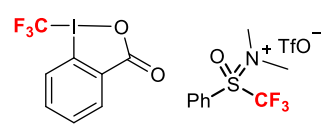

2c

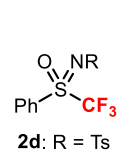<smiles></smiles>

$2 f$

\begin{tabular}{|c|c|c|c|c|c|}
\hline Entry & $\begin{array}{c}\mathrm{CF}_{3} \\
\text { source }\end{array}$ & Solvent & Base & $\begin{array}{l}\text { Yield } \\
{[\%]^{[a, b]}}\end{array}$ & $4 a^{\prime} / 4 a^{\prime}$ \\
\hline 1 & $2 a$ & $\mathrm{CH}_{2} \mathrm{Cl}_{2}$ & - & 2 & - \\
\hline 2 & $2 b$ & $\mathrm{CH}_{2} \mathrm{Cl}_{2}$ & - & 10 & $4.9: 1$ \\
\hline 3 & 2c & $\mathrm{CH}_{2} \mathrm{Cl}_{2}$ & - & 16 & $4: 1$ \\
\hline 4 & $2 d$ & $\mathrm{CH}_{2} \mathrm{Cl}_{2}$ & - & 53 & $4: 1$ \\
\hline 5 & $2 e$ & $\mathrm{CH}_{2} \mathrm{Cl}_{2}$ & - & 32 & $8: 1$ \\
\hline 6 & $2 f$ & $\mathrm{CH}_{2} \mathrm{Cl}_{2}$ & - & 54 & $12: 1$ \\
\hline 7 & $2 f$ & Acetone & - & 36 & $12: 1$ \\
\hline 8 & $2 f$ & DMF & - & 34 & $12: 1$ \\
\hline 9 & $2 f$ & THF & - & 26 & $12: 1$ \\
\hline 10 & $2 f$ & 1,4-dioxane & - & 54 & $12: 1$ \\
\hline 11 & $2 f$ & DCE & - & 54 & $12: 1$ \\
\hline $12^{[\mathrm{c}]}$ & $2 f$ & DCE & - & 56 & $12: 1$ \\
\hline $13^{[d]}$ & $2 f$ & DCE & - & 41 & $12: 1$ \\
\hline $14^{[c]}$ & $2 f$ & DCE & CsF & 28 & $12: 1$ \\
\hline $15^{[c]}$ & $2 f$ & DCE & $\mathrm{K}_{2} \mathrm{CO}_{3}$ & 31 & $12: 1$ \\
\hline $16^{[c]}$ & $2 f$ & DCE & $\mathrm{NaHCO}_{3}$ & 42 & $12: 1$ \\
\hline $17^{[c]}$ & $2 f$ & DCE & $\mathrm{K}_{2} \mathrm{HPO}_{4}$ & 39 & $12: 1$ \\
\hline $18^{[\mathrm{c}, \mathrm{e}]}$ & $2 f$ & DCE & $\mathrm{KH}_{2} \mathrm{PO}_{4}$ & $60(60)$ & $12: 1$ \\
\hline $19^{[c]}$ & $2 f$ & DCE & Pyridine & 31 & $12: 1$ \\
\hline $20^{[c, f]}$ & $2 f$ & DCE & $\mathrm{KH}_{2} \mathrm{PO}_{4}$ & 0 & - \\
\hline $21^{[c, g]}$ & $2 f$ & DCE & $\mathrm{KH}_{2} \mathrm{PO}_{4}$ & 0 & - \\
\hline
\end{tabular}

[a] General conditions: 1a $(0.1 \mathrm{mmol}), \mathrm{CF}_{3}$ source $2(0.1 \mathrm{mmol}), 3(0.025$ equiv), and base (2 equiv) irradiated with blue LEDs at RT for $18 \mathrm{~h}$. [b] Yields determined by ${ }^{19} \mathrm{~F}$ NMR spectroscopy using $\mathrm{PhOCF}_{3}$ as an internal standard. [c] With $0.15 \mathrm{mmol}$ of 1a. [d] With $0.15 \mathrm{mmol}$ of $\mathbf{2 f}$. [e] Yield into brackets referred to chromatographically pure product. [f] In the dark. [g] without 3.

such as solvent (entries 7-11), stoichiometry (entries 12-13), and base (entries 15-19) were further screened, and the optimal conditions $\left(\mathrm{KH}_{2} \mathrm{PO}_{4}\right.$ (2 equiv) in DCE, entry 19) afforded the desired allylic compound $\mathbf{4 a}$ in $60 \%$ isolated yield.

With these conditions in hand, the scope of this visible-lightinduced methodology was next examined and the results are summarized in Scheme 2. First, sulfilimino iminiums $2 \mathrm{~g}$-i bearing other fluorinated groups $\left(\mathrm{C}_{4} \mathrm{~F}_{9}, \mathrm{CFCl}_{2}\right.$ and $\mathrm{CF}_{2} \mathrm{Br}$, respectively) smoothly reacted with alkene $1 \mathrm{a}$, affording the corresponding

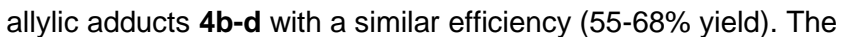

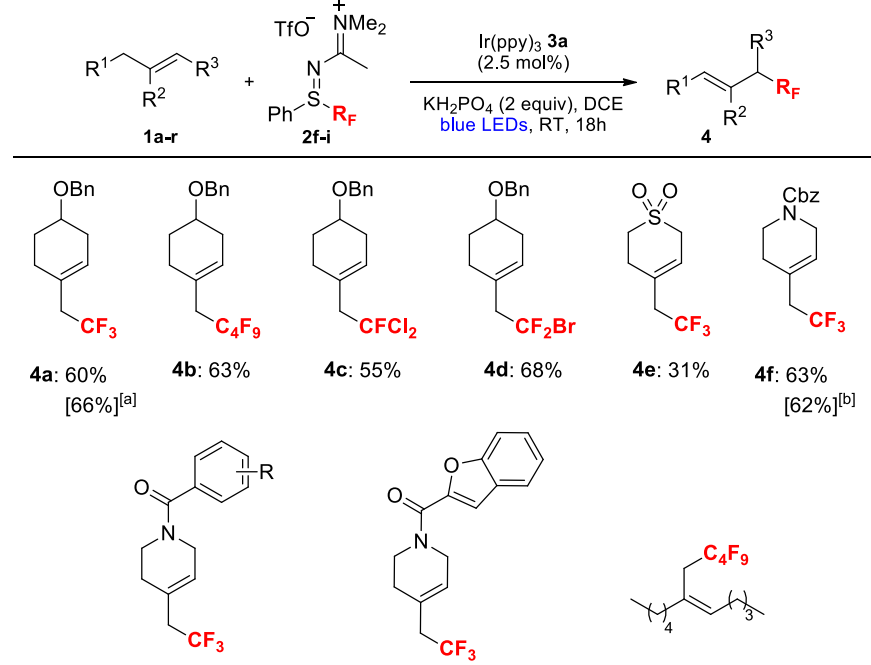

$\mathbf{4 g}(\mathrm{R}=4-\mathrm{CN}): 36 \%$ $\mathbf{4 g}(\mathrm{R}=4-\mathrm{CN}): 36 \%$
$\mathbf{4 h}(\mathrm{R}=4-\mathrm{BPin}): 47 \%$ $4 \mathbf{i}\left(\mathrm{R}=3-\mathrm{CO}_{2} \mathrm{Me}\right): 52 \%$

4j: $52 \% \quad 4 k: 53 \%(E / Z=1.3: 1)$

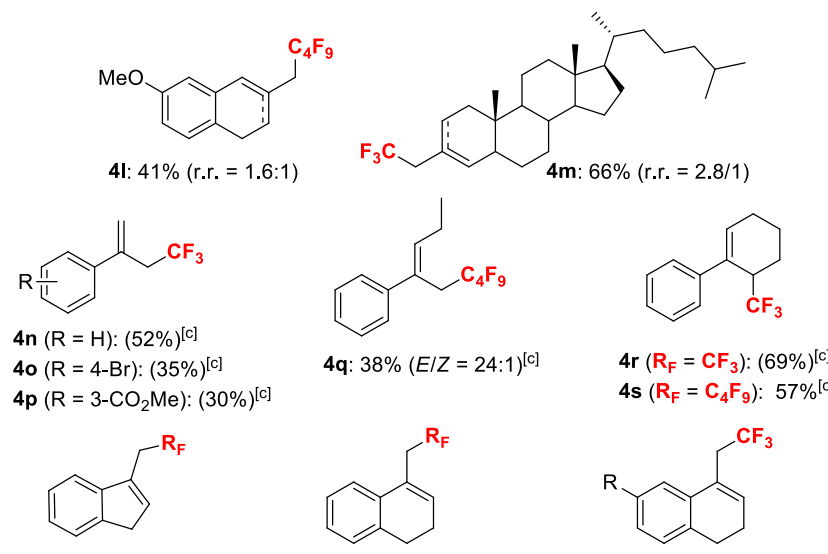

4t $\left(\mathrm{R}_{\mathrm{F}}=\mathrm{CF}_{3}\right):(49 \%)^{[\mathrm{c}]}$ $4 \mathbf{u}\left(R_{F}=C_{4} F_{9}\right): 45 \%[c]$

$4 \mathrm{v}\left(\mathrm{R}_{\mathrm{F}}=\mathrm{CF}_{3}\right):(53 \%)^{[\mathrm{C}]}$ $4 \mathbf{w}\left(R_{F}=C_{4} F_{9}\right): 61 \%{ }^{[c]}$

$4 \mathbf{x}(\mathrm{R}=\mathrm{OMe}): 39 \%(50 \%)^{[\mathrm{c}]}$ $4 y(R=B r): 67 \%[c]$

Scheme 2. Scope of the photoredox-catalyzed allylic perfluoroalkylation General conditions: alkene $1(0.15 \mathrm{mmol}), 2(0.10 \mathrm{mmol}), 3(2.5 \mathrm{~mol} \%)$ $\mathrm{KH}_{2} \mathrm{PO}_{4}(0.20 \mathrm{mmol})$ in DCE $(1 \mathrm{~mL})$ irradiated with blue LEDs at RT for $18 \mathrm{~h}$ Yields referred to chromatographically pure products. For volatile products, yields into brackets were determined by ${ }^{19} \mathrm{~F}$ NMR spectroscopy using $\mathrm{PhOCF}_{3}$ as an internal standard. [a] Performed on a $2 \mathrm{mmol}$ scale. [b] Performed on a $5 \mathrm{mmol}$ scale. [c] 2,6-di-tert-butylpyridine (1.5 equiv) in 1,4-dioxane instead of $\mathrm{KH}_{2} \mathrm{PO}_{4}$ (2 equiv) in DCE. r.r. = regioisomeric ratio.

scope of this allylic perfluoroalkylation reaction with respect to the unactivated alkene was also explored. Other exocyclic alkenes $\mathbf{1 b}-\mathbf{1 g}$ bearing various functionalities (sulfone, carbamate, amide, cyano, boronic ester, ester as well as benzofuran moiety) were all suitable partners for this visible-light induced process. Acyclic substrates, such as 6methyleneundecane $\mathbf{1 h}$, could also be readily converted into the corresponding allylic- $\mathrm{C}_{4} \mathrm{~F}_{9}$ adduct $\mathbf{4 k}$ in $53 \%$ yield. In addition, unsymmetrical substrates $\mathbf{1} \mathbf{i}-\mathbf{1} \mathbf{j}$ led to a mixture of perfluoroalkylated allylic regioisomers $4 \mathbf{l}$ and $\mathbf{4 m}$. Alkene $\mathbf{1 j}$ derived from $5 \alpha$-cholestan-3-one afforded the desired allyl- $\mathrm{CF}_{3}$ adduct $4 \mathrm{~m}$ in $66 \%$ yield, showing that such process is applicable to the late-stage functionalization of more complex molecules. 
Importantly, gram-scale experiments were also successfully performed to give compounds $\mathbf{4 a}$ and $\mathbf{4 f}$ without any loss of efficiency.

We then turned our attention to aromatic alkenes. Using our previous conditions, another by-product (the $\alpha$-hydroxy $-\beta-\mathrm{CF}_{3}$ arene adduct coming from the nucleophilic trapping of the benzylic cation intermediate with water) was detected in small amounts $\left(10 \%{ }^{19} \mathrm{~F}\right.$ NMR yield), leading to diminished yields and despite many efforts to work in dry medium. Fortunately, this side-reaction was efficiently minimized by replacing $\mathrm{KH}_{2} \mathrm{PO}_{4}$ with 2,6-di-tert-butylpyridine. Under these slightly modified reaction conditions, we were pleased to see that a wide variety of aromatic alkenes, such as acyclic styrenes $\mathbf{1 k}-\mathbf{n}$, endocyclic styrene 10, and exocyclic styrenes 1p-r smoothly reacted to furnish the corresponding perfluorinated allylic adducts $\mathbf{4 n - y}$ in up to $69 \%$ yield.

To study the mechanism of this perfluoroalkylation reaction, the following classical control experiments were performed. No reaction took place in the absence of irradiation and/or fac$\operatorname{Ir}(\mathrm{ppy})_{3} 3$ (see Table 1, entries 20-21). Additionally, a light on/off experiment was carried out (see S3 of the Supporting Information), which demonstrated that continuous irradiation is needed for the reaction to proceed. Moreover, the formation of $\mathbf{4}$ was inhibited in the presence of radical scavengers such as TEMPO ((2,2,6,6-tetramethylpiperidin-1-yl)oxyl), suggesting that a radical process is involved in this reaction.

In addition, the redox potential of sulfilimino iminium $2 f$ was measured by cyclic voltammetry $\left(E_{2 f}=-1.31 \mathrm{~V}\right.$ vs. SCE, SCE $=$ Saturated Calomel Electrode, see the Supporting Information for more details), and showed that the reduction of

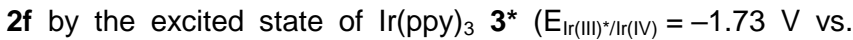
SCE) is thermodynamically feasible. Furthermore, luminescence quenching experiments were performed, and confirmed that only reagent $\mathbf{2 f}$ efficiently quenched the excited photocatalyst $3^{*}$ (Scheme 3a).

On the basis of all these studies, a plausible mechanism is depicted in Scheme 3b. Single Electron Transfer reduction of sulfilimino iminium $2 f-i$ by $3^{*}$ leads to the corresponding $\cdot R_{F}$ radical $\mathbf{A}$, which subsequently reacts with alkene $\mathbf{1}$ to give radical $\mathbf{B}$. Importantly, all these radical intermediates have already been characterized by electron paramagnetic resonance experiments using various spin traps. ${ }^{[10 a]}$ Then, radical $\mathbf{B}$ is oxidized into carbocation $\mathbf{C}$, which is finally deprotonated to afford the desired allylic adduct 4 . The oxidation step leading to intermediate $\mathbf{C}$ can follow two possible pathways: i) a photocatalytic pathway involving Ir $^{\mathrm{IV}}$ photocatalyst species; ii) or a radical chain mechanism involving a second molecule of sulfilimino iminium. To distinguish between these two pathways, the quantum yield $\Phi$ of the reaction was measured. ${ }^{[11]} \Phi$ is defined as:

$\Phi=($ rate of substrate conversion $) /($ absorbed photon flux $)$

In order to measure the rate of substrate conversion, the amount of remaining substrate $\mathbf{2 f}$ was plotted as a function of time, and these kinetics data were fitted to a $6^{\text {th }}$ order polynomial (Scheme $3 \mathrm{c}$, red line). This was enabled by the use of in operando ${ }^{19} \mathrm{~F}$ NMR spectroscopy, the reaction mixture being directly irradiated inside the NMR spectrometer thanks to an optical fiber (Scheme
$3 d$, see the Supporting Information for more details). ${ }^{[12]}$ The rate of substrate conversion was calculated from the derivative of this polynomial (see Table S1). Then, the photon flux was measured by standard ferrioxalate actinometry. ${ }^{[13]}$ This finally allowed us to calculate the quantum yield $\Phi$, which decreased over time, together with the amount of substrate $\mathbf{2 f}$ (see Figure S7).

(a)
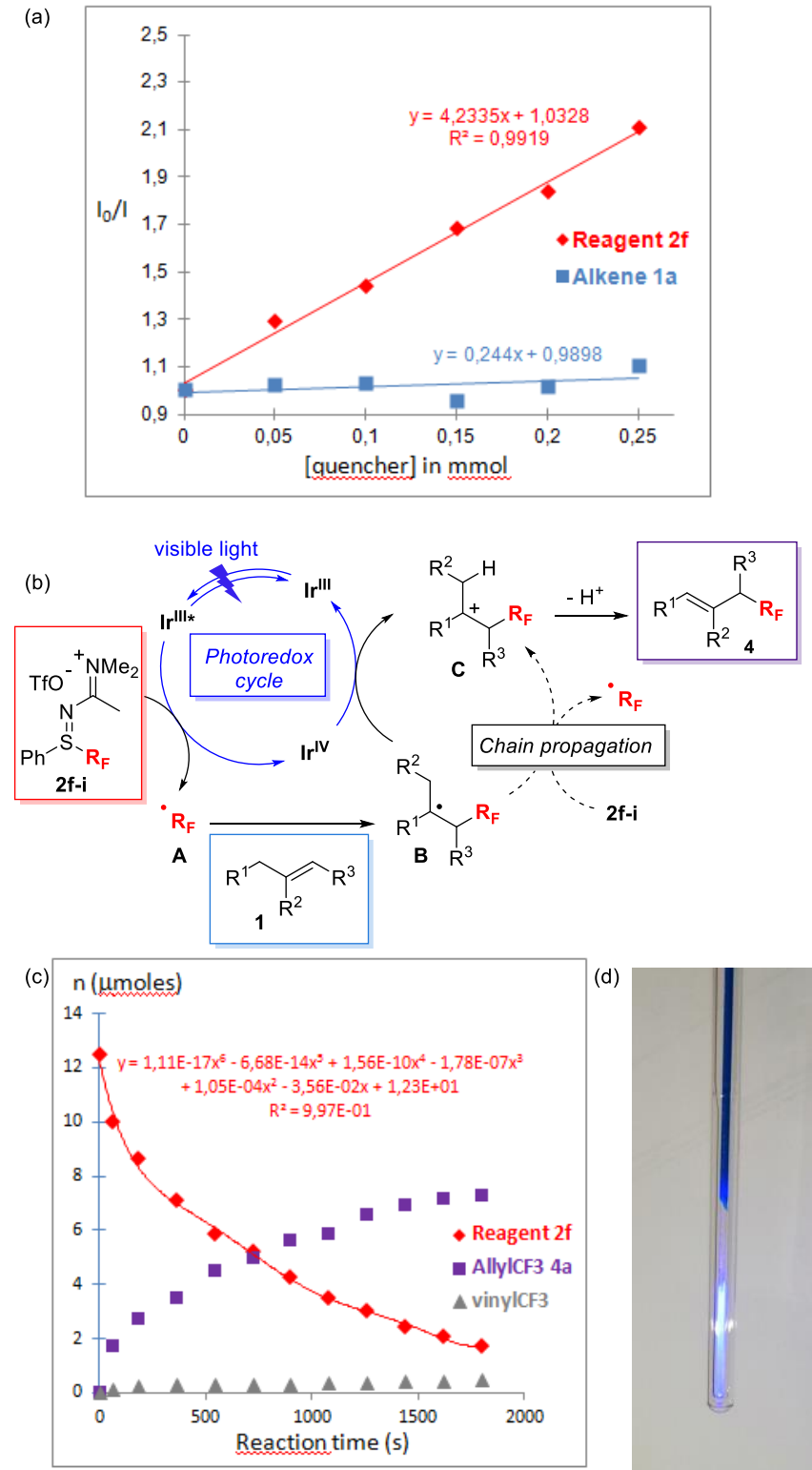

Scheme 3. (a) Luminescence quenching experiments. Stern Volmer plots $\mathrm{I}_{0} / \mathrm{l}=\mathrm{f}([$ quencher] $)$ using $\mathbf{1 a}$ or $\mathbf{2 f}$ as the quencher. (b) Plausible mechanism. (c) Recorded kinetic profiles of the reaction with a solution of $2 \mathbf{f}\left(1.25 .10^{-5} \mathrm{~mol}\right)$ alkene 1a (1.5 equiv), 3 (2.5 mol\%) and $\mathrm{KH}_{2} \mathrm{PO}_{4}$ (2 equiv), determined by ${ }^{19} \mathrm{~F}$ NMR spectroscopy using $\mathrm{PhOCF}_{3}$ as an internal standard. The red plot for $\mathbf{2 f}$ is fitted to a $6^{\text {th }}$ order polynomial. (d) Irradiation inside the NMR tube thanks to an optical fiber. 
The maximum value $\Phi=0.43$ suggests that the photocatalyzed process is mainly operating, and that the radical chain mechanism is less likely.

In conclusion, we have developed a new visible-light mediated allylic trifluoromethylation reaction. This efficient methodology operates with a high allyl/vinyl selectivity and is for the first time compatible with both unactivated alkenes and styrene derivatives bearing a wide range of functional groups. Importantly, this mild protocol has been successfully extended to other perfluoroalkyl motifs $\left(\mathrm{R}_{\mathrm{F}}=\mathrm{CFCl}_{2}, \mathrm{CF}_{2} \mathrm{Br}, \mathrm{C}_{4} \mathrm{~F}_{9}\right)$ thanks to the use of sulfilimino iminiums as sources of $R_{F}$ radicals.

\section{Acknowledgements}

A.L.B. thanks the French Ministry of Research for a doctoral fellowship. Youssef El-Ahmad and Victor Certal (Sanofi Vitry sur Seine) are acknowledge for stimulating scientific discussions and French Fluorine Network (CNRS GIS Fluor) for support.

Keywords: photoredox catalysis • allylic trifluoromethylation • sulfilimino iminium • perfluoroalkyl radicals $•$ visible light

[1] a) P. Kirsch, Modern Fluoroorganic Chemistry: Synthesis Reactivity, Applications, 2nd Ed., Wiley, New York, 2013; b) K. Müller, C. Faeh, F. Diederich, Science 2007, 317, 1881; c) Bioorganic and Medicinal Chemistry of Fluorine (Eds.: J.-P. Begue, D. Bonnet-Delpon), Wiley, Hoboken, 2008; d) J. Wang, M. Sanchez-Rosello, J. L. Acena, C. del Pozo, A. E. Sorochinsky, S. Fustero, V. A. Soloshonok, H. Liu, Chem. Rev. 2014, 114, 2432.

[2] Recent reviews on trifluoromethylation: a) H. Egami, M. Sodeoka, Angew. Chem. Int. Ed. 2014, 53, 8294; Angew. Chem. 2014, 126 8434; b) J. Charpentier, N. Früh, A. Togni, Chem. Rev. 2015, 115, 650; c) E. Merino, C. Nevado, Chem. Soc. Rev. 2014, 43, 6598; d) J. Xu, X Liu, Y. Fu, Tetrahedron Lett. 2014, 55, 585; f) C. Zhang, Adv. Synth. Catal. 2014, 356, 2895; g) X. Liu, C. Xu, M. Wang, Q. Liu, Chem. Rev. 2015, 115, 683 .

[3] Selected reviews on photoredox-catalyzed perfluoroalkylations: a) $T$. Koike, M. Akita, Top. Catal. 2014, 57, 967; b) M.-Y. Cao, X. Ren, Z. Lu, Tetrahedron Lett. 2015, 56, 3732; c) S. Barata-Vallejo, S. M. Bonesi, A. Postigo, Org. Biomol. Chem. 2015, 13, 11153; d) T. Chatterjee, N. Iqbal, Y. You, E. J. Cho, Acc. Chem. Res. 2016, 49, 2284; e) G. Dagousset, A. Carboni, G. Masson, E. Magnier, Modern Synthesis Processes and Reactivity of Fluorinated Compounds; (Eds.: H. Groult, F. Leroux, A. Tressaud), Elsevier, 2016, pp 389-426; f) X. Pan, H. Xia, J. Wu, Org. Chem. Front. 2016, 3, 1163 ; g) E. H. Oh, H. J. Kim, S. B. Han, Synthesis 2018, 50, 3346.

[4] M. Katalin, J. Katalin, C. Gabor, Drug Metab. Dispos. 1997, 25, 1370; b) M. Kelly, J. Kincaid, Z.-L. Wei, WO Patent 2006093832, 2006; c) H.J. Lu, R. B. Silverman, J. Med. Chem. 2006, 49, 7404; d) A. Hafner, S. Bräse, Adv. Synth. Catal. 2011, 353, 3044; e) R. Hemelaere, J. Desroches, J.-F. Paquin, Org. Lett. 2015, 17, 1770.

[5] Selected examples: a) R. T. Jacobs, P. R. Bernstein, L. A. Cronk, E. P. Vacek, L. F. Newcomb, D. Aharony, C. K. Buckner, E. J. Kusner, J. Med. Chem. 1994, 37, 1282; b) C.-J. Wang, X. Sun, X. Zhang, Angew. Chem. Int. Ed. 2005, 44, 4933; Angew. Chem. 2005, 117, 5013; c) C. Isanbor, D. O. O'Hagan, J. Fluorine Chem. 2006, 127, 303; d) Y Miyake, S.-I. Ota, Y. Nishibayashi, Chem. Eur. J. 2012, 18, 13255; e) M. M. Lerch, B. Morandi, Z. K. Wickens, R. H. Grubbs, Angew. Chem. Int. Ed. 2014, 53, 8654; Angew. Chem. 2014, 126, 8798.

[6] a) J. D. Nguyen, J. W. Tucker, M. D. Konieczynska, C. R. J. Stephenson, J. Am. Chem. Soc. 2011, 133, 4160; b) N. Iqbal, S. Choi,
E. Kim, E. J. Cho, J. Org. Chem. 2012, 77, 11383; c) C.Yu, N. Iqbal, S. Park, E. J. Cho, Chem. Commun. 2014, 50, 12884; d) W. J. Choi, S Choi, K. Ohkubo, S. Fukuzumi, E. J. Cho, Y. You, Chem. Sci. 2015, 6, 1454; e) F. Sladojevich, E. McNeill, J. Börgel, S.-L. Zheng, T. Ritter Angew. Chem. Int. Ed. 2015, 54, 3712; Angew. Chem. 2015, 127, 3783; f) Q.-Y. Lin, Y. Ran, X.-H. Xu, F.-L. Qing, Org. Lett. 2016, 18 2419; g) N. J. W. Straathof, S. E. Cramer, V. Hessel, T. Noël, Angew. Chem. Int. Ed. 2016, 55, 15549; Angew. Chem. 2016, 128, 15778; h) D. P. Tiwari, S. Dabral, J. Wen, J. Wiesenthal, S. Terhorst, C. Bolm, Org. Lett. 2017, 19, 4295; i) G.-R. Park, Y. Choi, M. G. Choi, S.-K Chang, E. J. Cho, Asian J. Org. Chem. 2017, 6, 436; j) E. Zhu, X. Liu, A. Wang, T. Mao, L. Zhao, X. Zhang, C. He, Chem. Commun. 2019, 55, 12259; k) K. Li, X. Zhang, J. Chen, Y. Gao, C. Yang, K. Zhang, Y. Zhou, B. Fan, Org. Lett. 2019, 21, 9914.

[7] M. Asano, R. Tomita, T. Koike, M. Akita, J. Fluorine. Chem. 2015, 179, 83.

[8] Other reports on visible-light-mediated synthesis of allylic perfluoroalkylated compounds involve pre-functionalized substrates: a) S. Mizuta, K. M. Engle, S. Verhoog, O. Galicia-Lopez, M. O’Duill, M. Medebielle, K. Wheelhouse, G. Rassias, A. Thompson, V. Gouverneur, Org. Lett. 2013, 15, 1250; b) P. Chandu, K. G. Ghosh, D. Sureshkumar, J. Org. Chem. 2019, 84, 8771; c) A. K.Yadav, A. K. Sharma, K.N Singh, Org. Chem. Front. 2019, 6, 989; d) M. Lübbesmeyer, E. G. Mackay, M. A. R. Raycroft, J. Elfert, D. A. Pratt, A. Studer, J. Am. Chem. Soc. 2020, 142, 2609.

[9] Syntheses of allyl- $\mathrm{CF}_{3}$ compounds from alkenes have also been reported under copper catalysis (only for aliphatic alkenes). See: a) T Parsons, S. L. Buchwald, Angew. Chem. Int. Ed. 2011, 50, 9120; Angew. Chem. 2011, 123, 9286; b) J. Xu, Y. Fu, D.-F. Luo, Y.-Y. Jiang B. Xiao, 80 Z.-J. Liu, T.-J. Gong and L. Liu, J. Am. Chem. Soc. 2011 133, 15300; c) X. Wang, Y. Ye, S. Zhang, J. Feng, Y. Xu, Y. Zhang, J Wang, J. Am. Chem. Soc. 2011, 133, 16410; d) L. Chu, F.-L. Qing, Org. Lett. 2012, 14, 2106; e) J. Lei, X. Liu, S. Zhang, S. Jiang, M. Huang, X Wu, Q. Zhu, Chem. Eur. J. 2015, 21, 6700; f) R. Beniazza, F. Molton, C. Duboc, A. Tron, N. D. McClenaghan, D. Lastécouères, J.-M. Vincent, Chem. Commun. 2015, 51, 9571; g) S. Kawamura, M. Sodeoka, Angew. Chem. Int. Ed. 2016, 55, 8740; Angew. Chem. 2016 128,8882 ; h) S. Kawamura, C. J. Henderson, Y. Aoki, D. Sekine, S. Kobayashi, M. Sodeoka, Chem. Commun. 2018, 54, 11276.

[10] a) M. Daniel, G. Dagousset, P. Diter, P.-A. Klein, B. Tuccio, A.-M Goncalves, G. Masson, E. Magnier, Angew. Chem. Int. Ed. 2017, 56, 3997; Angew. Chem. 2017, 129, 4055; b) A.-L. Barthelemy, G. Dagousset, E. Magnier, Eur. J. Org. Chem. 2020, 1429. C) A.-L. Barthelemy, V. Certal, G. Dagousset, E. Anselmi, L. Bertin, L. Fabien, B. Salgues, P. Courtes, C. Poma, Y. El-Ahmad, E. Magnier, Org. Process Res. Dev. 2020, 10.1021/acs.oprd.9b00403.

[11] a) M. A. Cismesia, T. P. Yoon, Chem. Sci. 2015, 6, 5426; b) M. D. Kärkäs, B. S. Matsuura, C. R. J. Stephenson, Science 2015, 349, 1285 c) A. Studer, D. P. Curran, Angew. Chem. Int. Ed. 2016, 55, 58; Angew Chem. 2016, 128, 58; d) H. G. Yayla, F. Peng, I. K. Mangion, M. McLaughlin, L.-C. Campeau, I. W. Davies, D. A. DiRocco, R. R. Knowles, Chem. Sci. 2016, 7, 2066.

[12] a) C. Feldmeier, H. Bartling, K. Magerl, R. M. Gschwind, Angew. Chem Int. Ed. 2015, 54, 1347; Angew. Chem. 2015, 127, 1363; b) A. Mills, C O'Rourke, J. Org. Chem. 2015, 80, 10342 ; c) H. Bartling, A. Eisenhofer, B. Kçnig, R. M. Gschwind, J. Am. Chem. Soc. 2016, 138 11860; d) J. Kind, L. Kaltschnee, M. Leyendecker, C. M. Thiele, Chem. Commun. 2016, 52, 12506; e) E. Procházková, L. Čechová, J. Kind Z.Janeba, C. M. Thiele, M. Dračínský, Chem. Eur. J. 2018, 24, 492; f) A. Seegerer, P. Nitschke, R. M. Gschwind, Angew. Chem. Int. Ed. 2018, 57, 7493; Angew. Chem. 2018, 130, 7615.

[13] Y. Ji, D. A. DiRocco, C. M. Hong, M. K. Wismer, M. Reibarkh, Org. Lett. 2018, 20, 2156. 
